The Quarterly Journal of Austrian Economics

Volume 23 | NO.3-4 | 355-389 | Fall/Winter 2020 WWW.QJAE.ORG

\title{
Finding the ENTREPRENEUR-Promoter: A PraXeological INQUiRY
}

\author{
Per L. Bylund* \\ JEL Classification: L11, L26, O12
}

\begin{abstract}
АвsтRACT: Entrepreneur-promoters, or the pioneers of economic improvement, provide an essential market function which economics cannot do without. Yet Ludwig von Mises maintains that this function lies beyond what can be defined with praxeological rigor. This paper attempts to find a praxeological subcategory of entrepreneurship that conforms with Mises's indeterminate references to the entrepreneur-promoter in Human Action. Rather than relying on the evenly rotating economy, which is commonly used for analyzing entrepreneurship, the imaginary construction of a specialization deadlock is employed, adapted from Per Bylund's Problem of Production. This construction allows for the derivation of a praxeological subcategory of entrepreneurship, distinct from the general function of uncertainty bearing, which suggests a theoretical explanation for what constitutes the driving force of the market process.
\end{abstract}

\section{ustrian economics has found a resurgence through the increased attention to entrepreneurship in policy and research}

\footnotetext{
"Per L. Bylund (per.bylund@okstate.edu) is assistant professor of entrepreneurship and Records-Johnston Professor of Free Enterprise in the School of Entrepreneurship in the Spears School of Business at Oklahoma State University. He is also a fellow of the Mises Institute and an associate fellow of the Ratio Institute in Stockholm.

The author has benefited from thoughtful comments on previous versions of this paper by Porter Burkett, Fernando D'Andrea, Sinclair Davidson, Hunter Hastings, and Mark Packard. He has also benefited from feedback from two anonymous reviewers. All remaining errors are the author's.
} 
(Klein and Bylund 2014). This should not be surprising. Although mainstream economic theory has long been uninterested in the topic (Baumol 1968; Hébert and Link 1988), entrepreneurship is core to the Austrian understanding of the market as a process (Kirzner 1992, 1997). Indeed, the school's founder himself discussed entrepreneurship in his groundbreaking magnum opus (see Menger [1871] 2007, 160-61). But it was not until much later that Austrians developed a theory of the entrepreneur, with Israel M. Kirzner's theory $(1973,1979,2009)$ being the most widely known. Kirzner (1973, 84-87) builds explicitly on Ludwig von Mises's ([1949] 1998, $254,255)$ praxeological definition of the entrepreneurial function (contra Menger) as "acting man exclusively seen from the aspect of the uncertainty inherent in every action," that is, "in regard to the changes occurring in the data of the market." Mises also famously observed that entrepreneurship, due to its uncertainty-bearing and therefore speculative nature, is the "driving force of the whole market system" (Mises [1949] 1998, 249). It is Mises's definition of entrepreneurship and its limitations that is of interest to us here.

Mises substantiates the conception of the entrepreneur as bearer of uncertainty using the imaginary construction of the evenly rotating economy (ERE), a fictional economy "characterized by the elimination of change in the data and of the time element" (Mises [1949] 1998, 247). The ERE thus encompasses all the elements of the real economy, including production, exchange, market prices, and so on, but without the uncertainty of change. Consequently, Mises ([1949] 1998, 247) notes, "The system [ERE] is in perpetual flux, but it remains always at the same spot. It revolves evenly round a fixed center, it rotates evenly." In this unchanging world of the ERE, therefore, there is no uncertainty and, consequently, "there is no room left for entrepreneurial activity" (Mises [1949] 1998, 247).

What is curious is that Mises at the same time affords the entrepreneur-promoter, ${ }^{1}$ a subcategory of entrepreneurship that "cannot be defined with praxeological rigor" (Mises [1949] 1998, 256), a premier role for understanding the market process. In fact, the promoter embodies, as it were, the incessant change in the market: "One enters the ranks of the promoters by aggressively pushing forward and thus submitting to the trial to which the market subjects

\footnotetext{
${ }^{1}$ I will henceforth, following Mises, refer to this function simply as "promoter."
} 
[everybody]" (Mises [1949] 1998, 309). The market process, in other words, progresses primarily through the actions of promoters, who push forward and thereby challenge the status quo. For this reason, "economics cannot do without the promoter concept" (Mises [1949] 1998, 256). However, Mises maintains, the promoter nevertheless lies beyond what economic theory can explain.

This article will show, first, that the importance of the promoter is that Mises saw in this role the actual driving force of the market: the cause of the progression of the market process and the economy's development. Rather than entrepreneurship in general, the uncertainty-bearing aspect of any action, it is the promoter's speculative undertaking of novel production processes and new ways of doing business that create the specific future market conditions under which all types of entrepreneurs can earn profits (or suffer losses).

Second, an economic (praxeological) definition of this category that largely conforms with Mises's indeterminate references to the promoter in Human Action ([1949] 1998) will be suggested. To distinguish promoters from nonpromoters, the imaginary construction of the specialization deadlock adapted from Per Bylund (2016) will be used. It has previously been used to determine the economic function of the firm as a means for implementing novel production structures beyond the extent of the market (Bylund 2011, 2015a, 2015b, 2016) but can be applied more broadly. The specialization deadlock can be understood generally as an adaptation of Mises's ERE where the assumptions have been significantly relaxed. Thereby, and due to the model's focus on the evolution of the market's production structure, it is a useful means for distinguishing between and explaining the driving force of production. In other words, the specialization deadlock can be applied to distinguish between categories of entrepreneurship, i.e., the types of productive progress taking place side by side in the market process, and it can identify their respective causes. Specifically, it is argued that the role of the promoter as pioneer of economic improvement can be defined praxeologically, by way of Bylund's (2016) model, as that entrepreneurial function which breaks the specialization deadlock and thus acts in pricelessness.

In what follows, it will first be substantiated that Mises saw in the promoter specifically, and not entrepreneurship more broadly, 
the driving force of the market. The ERE will then be used as a contrast to explain the workings of the specialization deadlock and how their respective assumptions differ. Thereafter, an economic definition of the promoter will be presented and then used to shed light on Mises's varied treatment of the market's driving force in Human Action. Finally, the praxeological definition of the promoter will be related to the entrepreneurship theories of Kirzner (1973) and Joseph A. Schumpeter ([1911] 1934).

Throughout this discussion, both Mises's nontheoretical notion and the praxeological category derived here will be referred to as "promoter." All references to apparent actors (entrepreneurs, promoters, etc.) are to their economic functions unless stated otherwise.

\section{THE PROMOTER AS DRIVING FORCE}

Mises holds that uncertainty "means acting man in regard to the changes occurring in the data of the market" (Mises [1949] 1998, 255). These data do not comprise only consumers' preferences, which do change unpredictably, but their preferences relative to the totality of the goods offerings by entrepreneurs (the structure of supply). The entrepreneur, therefore, bears uncertainty by speculating about the unknown future market conditions: the entire situation in which the entrepreneur's good will be offered for sale. As the market data for this future situation do not yet exist and behaviors of both producers and consumers are unpredictable, there is (and can be) no reliable knowledge in the present on which to base entrepreneurial decisions.

Uncertainty is different from imperfect knowledge, which is a problem that can be overcome at a cost. For example, a producer's lack of technological know-how can be remedied before or during production and is ultimately a calculated tradeoff between the cost of acquiring information and that of an estimated risk of problems in production. Although economic actors are affected by both imperfect knowledge and uncertainty, and it may often be difficult to distinguish between them in reality, the concepts are theoretically distinct and require separate analyses (Townsend et al. 2018). It is specifically due to the function of uncertainty bearing that "the entrepreneur earns profit or suffers loss" (Mises [1949] 1998, 255): 
the specific entrepreneurial profits and losses are not produced by the quantity of physical output. They depend on the adjustment of output to the most urgent wants of the consumers. What produces them is the extent to which the entrepreneur has succeeded or failed in anticipating the future-necessarily uncertain-state of the market. (Mises [1949] $1998,290)$

Entrepreneurs, who as uncertainty bearers are always speculators, are responsible for all adjustments of production in the economy. But such adjustments can be of different magnitudes, and Mises distinguishes between the "great adjustments," for which mainly the promoter is responsible, and the "many small adjustments [that] may seem trifling and of little bearing upon [production]," for which he is not:

\begin{abstract}
Adjustment of production to the best possible supplying of the consumers with the goods they are asking for most urgently does not merely consist in determining the general plan for the utilization of resources. There is, of course, no doubt that this is the main function of the promoter and speculator. But besides the great adjustments, many small adjustments are necessary too. Each of them may seem trifling and of little bearing upon the total result. But the cumulative effect of shortcomings in many of these minor matters can be such as to frustrate entirely the success of a correct solution of the great problems. At any rate, it is certain that every failure to handle the smaller problems results in a squandering of scarce factors of production and consequently in impairing the best possible satisfaction of the consumers. (Mises [1949] $1998,300)$
\end{abstract}

Having earlier noted that the promoter cannot be defined praxeologically, Mises ([1949] 1998, 300-07) focuses on distinguishing entrepreneurship, which can be defined, from nonentrepreneurial functions that also can. The latter, he argues, do not bear the uncertainty of the undertaking, but act on behalf of the entrepreneur. So "[t]he entrepreneur hires the technicians, i.e., people who have the ability and the skill to perform definite kinds and quantities of work" (Mises [1949] 1998, 300). The entrepreneur also typically appoints "[a] manager [who] is a junior partner of the entrepreneur, as it were, no matter what the contractual and financial terms of his employment are" (Mises [1949] 1998, 301).

Of interest to us here, however, is the distinction Mises makes between "regular" (nonpromoter) entrepreneurs and promoters. 
Mises is uncharacteristically imprecise, but this should be expected: having already asserted that promoters cannot be theoretically distinguished from nonpromoters, there is no basis for precision and no means to address the boundary conditions of the subcategories. We should not expect Mises (or anybody else) to use very precise language with respect to an undefined concept, because to do so is impossible. Mises is nevertheless clear that the "main function" of the promoter, which gets to his specific role, is to bring about "[a]djustment of production to the best possible supplying of the consumers with the goods they are asking for most urgently" and that it "does not merely consist in determining the general plan for the utilization of resources" (Mises [1949] 1998, 300; emphasis added). Indeed, as Joseph T. Salerno $(2008,195)$ summarizes, it is the promoter entrepreneur's role to have "the will and ability to assume leadership in the social division of labor by pushing or promoting oneself into a position of organizing and directing the factors of production." What characterizes the nonpromoter entrepreneurs, then, is that they are uncertainty bearers who are not making those great adjustments and thus not assuming such leadership-they instead focus on the "many small adjustments," which, at least individually, appear to have little effect on the organizing of market production overall. Nonpromoters also, although only in aggregate, "[determine] the general plan for the utilization of resources" in the economy.

This suggests that the nonpromoter entrepreneur has a primarily allocative role with respect to productive factors, the shifting of productive efforts from one line of production to another so that output better meets consumers wants. The promoter, in contrast, adjusts production beyond simply "determining the general plan for the utilization of resources" by instead "assum[ing] leadership in the social division of labor." Consequently, the promoter causes change to the structure of production. Following this reasoning, then, it can be posited that nonpromoters typically bear the uncertainty of the common, but not pioneering or disruptive, business enterprise. To use a common dichotomy in the entrepreneurship literature, nonpromoters would be more akin to imitator entrepreneurs, who may start new businesses but ones without structural implications, than they would be to disruptive innovators, who revolutionize production. Although nonpromoters provide a valuable (if not essential) function, their role is predominantly allocative, and they 
make adjustments within the existing structure of production rather than change it. They thus earn the profits of running the business, and also suffer the losses, and respond to changes in demand. Their actions cause continuous adjustments to the market's overall allocation of productive resources between lines of production.

Although this is illustrative of the main dividing line, it does little to provide a scientific definition of the role of the nonpromoter entrepreneur-those entrepreneurs who are not promoters and thus do not go beyond the "many small adjustments" and thereby do not determine the "general plan" of production. Nonpromoter entrepreneurs do, however, determine resource utilization, and this suggests that their function is primarily allocative (rather than disruptive). Promoters, in contrast, are "especially eager to profit from adjusting production to the expected changes in conditions, those who have more initiative, more venturesomeness, and a quicker eye than the crowd, the pushing and promoting pioneers of economic improvement" (Mises [1949] 1998, 255). The promoter is different from the nonpromoter in degree but not in kind:

The mentality of the promoters, speculators, and entrepreneurs is not different from that of their fellow men. They are merely superior to the masses in mental power and energy. They are the leaders on the way toward material progress. They are the first to understand that there is a discrepancy between what is done and what could be done. They guess what the consumers would like to have and are intent upon providing them with these things. (Mises [1949] 1998, 333)

As they focus on "guess[ing] what the consumers would like to have" (but are not offered) and adjusting production toward that end, promoters' impact on the economy is much greater than nonpromoters'. By being responsible for the major shifts in production, as opposed to the allocation and utilization of resources, the promoters exercise greater influence on the direction in which the market's overall production apparatus progresses (Bylund 2015b, 2016). Consequently, promoters, as the "pushing and promoting pioneers" and "leaders on the way toward material progress," epitomize the driving force of structural change in the market. Mises agrees:

The driving force of the market, the element tending toward unceasing innovation and improvement, is provided by the restlessness of the 
promoter and his eagerness to make profits as large as possible. (Mises [1949] 1998, 256)

And similarly:

The driving force of the market process is provided neither by the consumers nor by the owners of the means of production-land, capital goods, and labor-but by the promoting and speculating entrepreneurs. (Mises [1949] 1998, 325)

The promoter is the real driving force of the economy, the disruptor of the status quo who leads the way toward greater productivity and value creation by "guess[ing] what the consumers would like to have" and "pushing and promoting" the structure of production in this direction.

Considering the importance of this role in the unfolding of the market process, it is important to theoretically be able to distinguish the promoters from those entrepreneurs who do not constitute this "driving force." Yet as has been seen, Mises finds no basis for a theoretically rigorous distinction. The difference between promoters and nonpromoters, per Mises, exists only in the relative magnitudes: promoters' attempted and achieved adjustments to production are "great" (not "small" or "trifling") and they are "leaders on the way toward material progress" (as opposed to followers orimitators). Based on this observation, Mises properly concludes that the distinction lies beyond what can be determined with praxeological rigor.

However, as shall be seen, this is an unwarranted conclusion that follows from a misapplication of the imaginary construction used. Mises's conclusion, I argue, is based on specific limitations of the $E R E$, not of praxeology per se. In fact, the ERE's assumptions are appropriate for distinguishing the function of entrepreneurship from other functions, but it thereby disallows distinguishing different types within this function.

\section{FROM THE EVENLY ROTATING ECONOMY TO THE SPECIALIZATION DEADLOCK}

Mises astutely notes that "[t]he use of imaginary constructions to which nothing corresponds in reality is an indispensable tool of 
thinking" (Mises [1949] 1998, 202). These constructions, including the ERE, are indispensable because they allow for rational analysis of complex processes, delineation of causal relationships, and examination of interactions that may not exist independently and cannot be observed in complex real-world situations. Their power for developing our understanding of and interpreting the economy is practically irrefutable.

However, as Mises also notes, "one of the most important problems of science is to avoid the fallacies which ill-considered employment of such constructions can entail" (Mises [1949] 1998, 202-03). The misapplication of imaginary constructions can cause "serious blunders."

Using the ERE to distinguish between types of entrepreneurship would be such a serious blunder, because the ERE is formulated to eliminate uncertainty, by excluding change, and thereby separate uncertainty bearing from other functions in the market. As Mises ([1949] 1998, 249) summarized it, "In order to grasp the function of entrepreneurship and the meaning of profit and loss, we construct a system from which they are absent." The ERE is indeed appropriate for this particular end, but this also makes it unsuitable for the purpose of distinguishing between types of uncertainty bearing. It relies on assumptions that all but exclude those adjustments to the production structure that are the main function of the promoter, and thus it cannot assist in distinguishing promoters from nonpromoters. ${ }^{2}$

\section{The Evenly Rotating Economy}

The ERE creates a fictional economy in which all causes of change in the market data have been theoretically removed. As these data are constants rather than variables there is no uncertainty about the future (it will be just like the present), which means that there are also no opportunities for entrepreneurs: adjustments to the production apparatus or resource allocations could not better satisfy consumers than the status quo. The economy that emerges is thus necessarily entrepreneurless. Mises explains:

\footnotetext{
${ }^{2}$ Mises cannot be blamed for making such an error (because he did not), but he appears to have overlooked the possibility of creating and employing other imaginary constructions to analyze entrepreneurship subcategories.
} 
In the frame of this imaginary construction no change occurs; there prevails an unvarying course of all affairs. In the evenly rotating economy consequently nothing is altered in the allocation of goods for the satisfaction of wants in nearer and in remoter periods of the future. No one plans any change because-according to our assumptions - the prevailing allocation best serves him and because he does not believe that any possible rearrangement could improve his condition. No one wants to increase his consumption in a nearer period of the future at the expense of his consumption in a more distant period or vice versa because the existing mode of allocation pleases him better than any other thinkable and feasible mode. (Mises [1949] 1998, 482)

Murray N. Rothbard elaborates on the difference between the ERE and the real economy and adds specificity to what the ERE entails and its rationale:

the real world of action is one of continual change. Individual value scales, technological ideas, and the quantities of means available are always changing. These changes continually impel the economy in various directions. Value scales change, and consumer demand shifts from one good to another. Technological ideas change, and factors are used in different ways. Both types of change have differing effects on prices. Time preferences change, with certain effects on interest and capital formation. The crucial point is this: before the effects of any one change are completely worked out, other changes intervene. What we must consider, however, by the use of reasoning, is what would happen if no changes intervened. In other words, what would occur if value scales, technological ideas, and the given resources remained constant? (Rothbard [1962, 1970] 2004, 321)

The ERE, per Rothbard, holds four types of changes constant: consumers' value scales, technological ideas used in production, available supply of resources, and individuals' time preferences. If we were to theoretically fix those four variables in the present economy, an evenly rotating economy would emerge after a period of transition. During this transition stage, actors (as both producers and consumers) find their maximizing behavior through valueseeking trial and error. As the data of the market do not change, the actions that maximize each actor's satisfaction remain constant and are thus attainable. As actors try to find their max, this process eventually brings about a state of affairs in which each individual will no longer choose to adjust their behavior but will repeat those actions that they have learned maximize their satisfaction. This 
final stage is not without production, consumption, and so on but is unaffected by the aforementioned types of changes so there is no uncertainty - the economy is "evenly rotating."

The specific assumptions of this imaginary construction allow the theorist to analyze the impact of individual variables, jumbled and indistinguishable in the constant flux of the empirical world, by introducing specific changes and then reasoning through the implications. For example, by theoretically changing the rate of time preference in the ERE, the theorist can logically reason through how actors' behaviors change and can therefore analyze the effect on the time structure of production of a change in time preference alone. Similarly, one can change or relax other ERE assumptions and thereby analyze the impact of specific changes in value scales, technological ideas, etc.

The limitation of the ERE's usefulness is evident from its assumptions: the ERE can be used to analyze specific changes and responses to them, because all other changes have been theoretically eliminated. Although each of the changes assumed constant can be relaxed, the ERE can only be used to analyze uncertainty bearing per se with respect to those particular variables (value scales, technology, etc.). But entrepreneurship cannot be decomposed using the ERE, as the former is defined as those speculative undertakings "exclusively seen from the aspect of the uncertainty inherent in every action" and thus "in regard to the changes occurring in the data of the market" (Mises [1949] 1998, 254, 255). Outcome magnitudes, such as Mises's distinction between great and small adjustments, or types of actions, such as the distinction between directing production and allocating resources, remain out of reach when using the ERE. But this does not mean that all imaginary constructions must fail at this task. This article argues that the specialization deadlock is suitable for determining the function of the promoter.

\section{The Specialization Deadlock}

Bylund (2016) formulates a praxeological explanation for the economic function of the business firm. In order to do so, he adopts Mises's ([1949] 1998, 238-39) imaginary construction of the pure market economy, unhampered by political restrictions but without 
any form of organizations or coordinated production structures that can be interpreted as firms. The assumption underlying this model is that coordination can only take place through the price mechanism, which is commonly recognized as the alternative to intrafirm organization (cf. Coase 1937). Then, applying the Misesian fact that "[s]ociety is concerted action, cooperation" that arises due to the fact "that work performed under the division of labor is more productive than isolated work and that man's reason is capable of recognizing this truth" (Mises [1949] 1998, 143, 144), Bylund analyzes the dynamics of productive adjustments (in other words, entrepreneurship) in the price-coordinated market. The aim is to analytically uncover the processes by which an unhampered economy adopts, improves, and implements more intensive specialization under the division of labor. In other words, to answer the question of economic development: how a market progresses through ever more intensive specializing to achieve greater productivity and thereby attains higher standards of living.

Bylund (2016) finds that this decentralized, price-coordinated market hits a development ceiling ${ }^{3}$ beyond which autonomous actors are unable to adopt more intensive specialization. To progress beyond this limitation, and thus achieve greater specialization intensity, requires advanced splitting of production tasks-typically the introduction of new production processes to replace existing tasks-and thus coordination beyond what the price mechanism can provide (Bylund 2011, 2015a). Any such action would take place in pricelessness, beyond the realm of economic calculation through market prices, because there is no existing market for novelty. This type of entrepreneurial undertaking goes well beyond the simple arbitrage of, e.g., Kirzner's (1973) entrepreneur, which requires no additional coordination, and it is also beyond the firm as theorized by, e.g., Ronald H. Coase (1937), which is practically a mirror image of market production (Bylund 2015c, forthcoming). To establish a new production process requires imagination, financing, and coordination as well as leadership (Witt 1998), and it can often also include experimentation and development of new capital.

\footnotetext{
${ }^{3}$ This ceiling is contingent on population density, as discussed by Durkheim ([1892] 1933), and is thus a moving target. Yet it constitutes an effective conclusion, or at any rate a dramatic slowdown, of the market's progression.
} 
Compared to the ERE, Bylund's imaginary construction, called the specialization deadlock ${ }^{4}$ (referring to the ceiling), allows change in all four types of market data that the ERE holds constant. Uncertainty is therefore present in the specialization deadlock construction, and consequently it includes entrepreneurship. However, the focus on specialization introduces a new distinction that decomposes technological ideas (which guide and limit the scope of production undertakings) into those that (1) can be implemented through decentralized means (through price mechanism coordination) and those that (2) require centralized (nonprice) coordination of the implementation process in order to bring about the imagined production structure.

The former type includes specialization by the individual actor or that can be attained through coordination with others using simple exchange or market contracts. These are the types of divisions of labor that Adam Smith famously discusses in The Wealth of Nations. To Smith, "the division of labour is limited by the extent of the market" (Smith [1776] 1976, bk. 1, chap. 3). This "extent" can be understood as the degree to which "individuals [are] sufficiently in contact to be able to act and react upon one another...and the active commerce resulting from it" (Durkheim [1892] 1933, 257; cf. Land 1970). This limitation allows for a sphere of dynamic actions, including uncertainty-bearing entrepreneurship in response to changing market data, within the limitation of the specialization deadlock. These specializations that do not require centralized coordination can also build on previous specialization efforts incrementally, thereby pushing the extent of the market outwards.

Importantly, however, this incremental progression would not generate the pin factory that Smith uses to exemplify the productive powers of specialization under the division of labor. The incremental progression of the division of labor would not facilitate specializations far beyond what has already been implemented in the market, since this would require the form of coordination excluded from the specialization deadlock. In other words, while the incremental intensification of specialization could eventually generate a highly specialized process, similar to the one taking place within Smith's pin factory, it would do so without need for the centralized organizing

\footnotetext{
${ }^{4}$ For details, see Bylund (2016, 60-65)
} 
of the factory and also without being substantially different from specializations already supported in the market.

This incremental progression within the specialization deadlock can, however, be upset by the implementation of novel technological ideas (including new types of organization) that require centralized coordination to be feasible. In other words, to establish for the first time a highly specialized production process, akin to what Smith observes in the pin factory, is to go beyond and thus break out of the specialization deadlock. This would require centralized coordination and up-front financing: the creation of a factory. From the point of view of the market's existing production structure, then, there is a categorical difference between changes in the form of adjustments that are compatible with the existing division of labor and therefore take place within the extent of the market, coordinated through the price mechanism and simple contracting, and those attempted changes that fall outside the market's extent, challenge the status quo, and will, if successful, bring about disruptions to it. Rothbard helps illustrate this difference:

\footnotetext{
While a continuing and advancing division of labor is needed for a developed economy and society, the extent of such development at any given time limits the degree of specialization that any given economy can have....Economic and social development is therefore a mutually reinforcing process: the development of the market permits a wider division of labor, which in turn enables a further extension of the market. (Rothbard 1991, 26)
}

Per the assumptions of Bylund's imaginary construction, this "mutually reinforcing process" is limited to such division of labor as does not require coordination of factors beyond what can be achieved through the price mechanism and simple contracting. In other words, the opportunities for adopting more intensively specialized production in the decentralized market process are subject to (and thus limited by) the specialization deadlock-the specialization intensity beyond which decentralized economic actors cannot go without effecting incompatibility with the existing production structure. This provides insight into what types of entrepreneurial undertakings are excluded from the specialization deadlock model: those implementations that cannot be coordinated through market prices. They would, assuming that they take place, be located beyond the deadlock and therefore break it. 
We can conceive of two types of distinct changes that entrepreneurs can effect in the structure of production that go beyond and so break the specialization deadlock and thus require coordinated action. First, the production of a new type of consumers' good that cannot be assembled through simple means from standard components already available in the market. The production process would introduce novelty in both the consumer's good, which has not previously been offered for sale and for which demand is therefore unknown (no value has been realized), and in its production. Second is the introduction of an innovation in the form of novel organizing of existing production stages through the splitting of tasks (Bylund 2011, 2015a), new combinations of factors (Schumpeter [1911] 1934), or creation of new and adapted capital structures (Lachmann [1956] 1978). Both types of changes depend on the utilization of novel technology, broadly conceived, whose implementation institutes a change in the production apparatus in some significant way. In other words, these types of changes constitute "great adjustments" of production by the entrepreneur who, in undertaking their implementation, "assume[s] leadership in the social division of labor by pushing or promoting oneself into a position of organizing and directing the factors of production" (Salerno 2008, 195).

The latter case will be elaborated here to illustrate the specialization deadlock, which is also the focus of Bylund's (2016) discussion. Assuming an existing roundabout production process in which a good is produced through several conceptually separate stages, each with their own specializations, novelty would be introduced in new ways of organizing and therefore replacing (at least) one stage. In other words, an entrepreneur conceives of a new and potentially more productive way of producing such that an existing stage is replaced by several more intensively specialized tasks (a new subprocess). So the new way of producing must be compatible with the remainder of the production process-unless this new process is in the highest- or lowest-order stages, the new process must procure inputs in the open market from producers at prior stages and also sell the produced outputs to producers in subsequent stages. In other words, for an innovation to be successfully implemented, it must achieve three things. First, it must be adapted or positioned to use inputs that are already available for purchase in the market. Second, 
it must similarly produce outputs that the subsequent production stage is equipped to use in its production. These are both required in order for the innovative production process to be compatible with the existing production structure. Third and final, the novel production process must be organized and coordinated such that it constitutes a complete chain of productive tasks that produce compatible outputs from existing inputs. Also, for this undertaking to be successful, the new process must be more valuable overall than the mode of production already existing in the market that it (competes with and) attempts to replace.

Bylund (2015a) illustrates this with a theoretical existing production process that consists of only three stages (tasks) from start (only original factors) to finish (consumer's good), $t_{1}-t_{2}-t_{3}$. The entrepreneur envisions a means to improve production by changing the process. Specifically, the entrepreneur's imagined solution consists of replacing the existing stage $t_{2}$ with three separate and much more highly specialized (and therefore expected to be more productive) tasks in a subprocess: $t_{21}-t_{22}-t_{23}$. Thus:

The [envisioned] efficient process comprises $t_{1}-\left[t_{21}-t_{22}-t_{23}\right]-t_{3}$ where the intermediate tasks $t_{21}-t_{22}-t_{23}$ are more highly specialized $\left(s_{\mathrm{j}}>S_{\mathrm{m}}\right)$ and therefore jointly more productive than the market-traded task $t_{2}$. The input for $\left[t_{21}-t_{22}-t_{23}\right]$ remains the output of $t_{1}$, and the process's output is the input of $t_{3}$-both are traded (or tradable) in the market, and so the new and more specialized process is compatible with the market and complete in replacing task $t_{2}$. In fact, in order to successfully compete with and supplant $t_{2}$ by exploiting the productive capability of $\left[t_{21}-t_{22}-t_{23}\right]$, the mutually specialized subprocess must be compatible with the existing productive structure (i.e., $t_{1}$ and $t_{3}$ ) or, alternatively, rely on substitute inputs that do not require new production structures (they should already be available in the market). Incompatibility with either $t_{1}$ or $t_{3}$ suggests failure by disconnecting the encapsulated subprocess from the market. (brackets in original)

This thought experiment provides several important insights, but it is sufficient for our purposes to note that this type of novel production process requires more than the coordination offered by the price mechanism (Bylund 2016, 67-85). Indeed, as the new tasks and structure $\left[t_{21}-t_{22}-t_{23}\right]$ are new, there can be no existing market prices for their contributions. These tasks are also not marketable, since they have not previously been observed. This suggests not 
only that the entrepreneur will need to provide coordination to accomplish the envisioned structure but also that up-front financing will be needed in order to attract factors from their current market positions. Factors will command prices higher than the prevailing market wage to become part of the new and untried (and thus more vulnerable) position (Bylund 2016, 107-20; cf. Bylund and Bylund, forthcoming). This undertaking is speculative, uncertainty-bearing entrepreneurship, but it is significantly different from the types of uncertainty bearing through arbitrage and production that can take place within the extent of the market. It is of a specific kind because it (per our assumption) utilizes specialization beyond the intensity that the economy is currently able to support-beyond what can be coordinated through existing market prices. In other words, this entrepreneurship must have an internal coordinative component in addition to the coordinative implications of resource allocation for the market. It is also blind to the relative economic efficiency of the parts of the (sub)process that it implements because there are (and can be) no market prices. In other words, when this new structure is implemented, it becomes an "island of specialization," or what Bylund (2016) argues is properly (and praxeologically) a firm. We do not need to take that full step to the firm here, however, but need only recognize the specialization deadlock and that although it is an obstacle, it is not insurmountable. Indeed, as has been shown, markets can and do overcome the deadlock, specifically through innovative coordinated entrepreneurial undertakings that establish new and more intensive divisions of labor.

\section{DETERMINING THE ROLE OF THE PROMOTER}

The discussion in the previous section suggests a framework for analyzing the economic nature of what Mises ([1949] 1998, 300) refers to as "great adjustments" of production as compared to "small adjustments." It is also clearly relevant to Salerno's $(2008,195)$ view of the promoter as having "the will and ability to assume leadership in the social division of labor by pushing or promoting oneself into a position of organizing and directing the factors of production." Seen through the lens of the specialization deadlock, rather than the ERE, we can distinguish between entrepreneurship as uncertainty bearing within the limits of the market's existing specialization intensity 
(that is, within the present extent of the market and without challenge to the specialization deadlock) and uncertainty bearing (through coordinated production undertakings) beyond the market's existing specialization intensity (that is, outside the extent of the existing market and thus taking place despite and in direct conflict with the specialization deadlock).

These are not arbitrary classifications but are distinct by being either compliant with or directly challenging the specialization deadlock, which is an implication of the interdependence of factors that arises under the division of labor. Importantly, they are also not adjacent from a specialization point of view. There are two reasons for this. First, as Bylund (2011, 2015a, 2016) emphasizes, the "splitting" of a task into many, thereby replacing a standard task with a process, is not an incremental but a discrete change-there are no feasible solutions in between. Also, even if in-between solutions were possible, new production that utilizes specialization intensity just beyond what is compatible with the existing production structure would be unlikely to provide sufficient efficiency gains to cover the costs of implementing and bearing the uncertainty of such production. Thus, these are discrete types of entrepreneurial undertakings, because between the innovative, deadlock-defying "great adjustments" and the market-compatible "small adjustments" exists an "infeasibility zone" where no production undertakings will or can take place:

This 'zone' arises due to the fact that all productive innovations that are impossible to realise through market means suffer from unknowability and that their internal strict interdependence suggests incompleteness even from failure in one of their parts. (Bylund 2016, 100)

In other words, the costs of implementing novel production beyond the specialization deadlock are significantly higher than production within the extent of the market. For such an undertaking to make economic sense, the entrepreneur must rely on significant gains from specialization to cover those costs. Unless the new division of labor takes a significant leap forward as compared to the within-market intensity of specialization, the costs exceed the gains and the undertaking would thus generate a loss to the entrepreneur. 
In sum, there are two distinct categories of entrepreneurial action. Entrepreneurial action in the first category consists of implementing innovative production structures through advanced task splitting (division of labor) and specializing beyond the specialization deadlock by some magnitude. The other category consists of the efficiency-improving adjustments that take place within the specialization deadlock.

\section{Nonpromoter Entrepreneurs}

The entrepreneurial actions taking place within the specialization deadlock, and thus within the existing extent of the market, are, relatively speaking, small and, in Mises's words, "may seem trifling and of little bearing upon the total result." They include the allocations of resources between production processes for arbitrage gain as well as so-called imitative entrepreneurship, including where the entrepreneur introduces to an industry ideas and technologies already implemented elsewhere. But these actions, which individually are of little magnitude from the perspective of the economic system, are still highly important for the market process as "the cumulative effect of shortcomings in many of these minor matters can be such as to frustrate entirely the success of a correct solution of the great problems" (Mises [1949] 1998, 300). Although the individual nonpromoter entrepreneur does not exercise much influence, the aggregate effect of such actions, including the weeding out of less productive entrepreneurs, is essential.

Entrepreneurs of this type respond to and attempt to second-guess changes in market conditions so as to position their ventures in the best possible way. They allocate factors between and organize production within the structure of production. They also competitively bid for resources in the open market, which effectuate changes to market prices that facilitate improved economic calculation. As a result, their efforts bring about continuous minor changes to the production structure through shifting allocations of resources in response to expected or foreseeable changes in the market data and through incrementally adopting more intensive specializations. But these adjustments are limited in economic scope, as they do not attempt to innovatively disrupt the existing 
structure of production-these adjustments happen within the extent of the market and are compatible with production in the status quo. Nevertheless, they serve a very important function in the market economy though their constant adjustments and attempted responses to changes (Hayek 1945).

This entrepreneur, acting within the confines of the specialization deadlock, is primarily a responsive agent who is alert to and thus discovers opportunities revealed within the present extent of the market (cf., Kirzner 1973). Whether these opportunities are due to changes in the market data, such as changing consumer preferences or shocks to production, nonpromoter entrepreneurs profit from swiftly adjusting their efforts to the change or exploiting a previously undiscovered misallocation of resources. It is thus, from the point of view of the new market data and whether the data are themselves new or simply new to the actor (or perhaps all actors), accurate to refer to such actions as corrections of errors made by previous entrepreneurs (Kirzner 1978). They could also be characterized as discoveries, since they are in fact already existing, as it were, within the fabric of the market but have, for whatever reason, remained unnoticed and unexploited (Shane and Venkataraman, 2000; Shane, 2003). These adjustments would consequently always, when successful, be equilibrating, since the discovery and correction of an error (or inefficiency) cannot be anything else (Kirzner 1973, 1978).

Yet given the discussion above, the limited impact of this type of entrepreneur on the market process and the structure of production is obvious. Corrections of errors, continuous adjustments of existing production processes, and the (re)allocation toward more valuable production in response to new (or expected new) data are just that: responsive. This is not to say the nonpromoter entrepreneur is passive, only that the opportunity for profit, existing in the form of a discovered disequilibrium (an "error"), emerges before the action to exploit it. The impact of the alertness on which this type of entrepreneur acts is limited by what opportunities he discovers, but the opportunities themselves are not actively created (cf. Alvarez and Barney 2007). From the perspective of this entrepreneur, disruptions are of exogenous origin (Shane 2003); nonpromoter entrepreneurs only respond to them as they discover them. 


\section{Promoters}

The promoter's role as producer of "great adjustments" to the market's production, as a leader in the social division of labor, is distinct from that of the nonpromoter-and significant. Promoters are the entrepreneurs who, through attempting to coordinate and organize disruptive production processes, establish production significantly beyond the limit of the market's existing specialization intensity and thus are positioned (and intended) to break free from the specialization deadlock. Rather than responding to the discovered opportunities within the market's extent, already existing in its fabric, they imagine new ways of structuring and organizing production. This may take the form of a new type of consumer's good or a new type of production, as noted above, but common to their efforts is an active pursuit of what does not yet exist. Their imagined production also cannot be obvious or limitedly innovative, since such novelty would either be reachable through within-system specializing, and therefore would be in the realm of the nonpromoter, or would fall within the unfeasibility zone and so would be economically unfeasible. Typically, producing a new good or replacing an existing production stage with a new, more roundabout process would entail task splitting and, consequently, would not be an incremental change. As a result, entrepreneurs attempting this must break new ground and, where successful, bring about changes in the data on which other entrepreneurs (primarily nonpromoters) base their decisions. Their actions, and the economic impact thereof, thus go well beyond what nonpromoter entrepreneurs undertake. The promoter's entrepreneurial undertaking is different and constitutes much more than being "more adept than others at anticipating and adjusting to change" (Salerno 1993, 123).

Although their actions may indirectly affect consumers' value scales (by offering new goods), their time preferences (by, for example, improving the standard of living), and the supply of resources (through refined production techniques), they comprise the development and implementation of novel technology—recipes for production (Rothbard [1962, 1970] 2004, 11). To be positioned beyond the specialization deadlock, and thus outside the extent of the market, these ideas must be novel and original and thus, to 
again refer to Bylund (2016), utilize more intensive specialization. But note that the "entrepreneur's technological ability does not affect the specific entrepreneurial profit or loss" (Mises [1949] 1998, 288; emphasis added). It is not the technological production recipe that makes the promoter, but that the implemented ideas are novel from an economic perspective (they must better satisfy consumers), which means that the entrepreneur cannot rely on the price mechanism for coordination. He can only to a limited extent apply existing knowledge of what is economically feasible-there is only imagination and judgment to guide his uncertainty bearing.

To use Schumpeter's (1947) well-known phrase, these entrepreneurs cause "creative destruction" to market production by challenging and, where successful, undermining and undoing the status quo. ${ }^{5}$ From a Misesian perspective, promoters disrupt the existing market's production structure by envisioning and implementing novel production beyond the extent of the market, thereby undermining and ultimately dissolving the specialization deadlock. Our analysis categorizes as promoter entrepreneurship specifically such novelty as is not incrementally pushing the boundary of but defies the specialization deadlock and thus must be implemented in the realm of pricelessness. This type of undertaking cannot be accomplished, as Bylund (2016) argues, without up-front financing of the endeavor - the successful implementation of new production depends on productive completeness through coordination, compatibility with the surrounding production structure, and sufficient use of intensive specialization to produce gains in excess of cost. In this sense, to borrow a phrase from Rothbard $(1974,903)$, "the entrepreneur and the capitalist are one and the same"- there can be no promoter without a capitalist investment in novel production.

The unique role of the promoter, then, is not to perfect existing production, which is rather the role of nonpromoter entrepreneurs. Instead, promoters challenge the status quo by replacing production processes, stages, or tasks with novel production structures that are imagined more in line with the wants that consumers are

\footnotetext{
${ }^{5}$ Interestingly, Schumpeter $(1961,107)$ also noted that that "[t]he promoter may indeed be...the purest type of the entrepreneur genus. He is then the entrepreneur who confines himself most strictly to the characteristic entrepreneurial function, the carrying out of new combinations."
} 
eager to satisfy. Specifically, promoters imagine and implement production processes that are more intensively specialized than is realizable through the price mechanism and market contracting. The application of the specialization deadlock here makes clear that this promoter role can be defined praxeologically as that which revolutionizes the structure of production by bringing about more roundabout production processes.

As the new process implemented by the promoter is untried, its economic efficiency relies solely on the entrepreneur's judgment. Therefore, it is likely to be quite ineffective, both technologically and economically speaking. As is the case with first-generation devices, any success is a proof of concept and reason to further refine the ideas and their implementation. Consequently, the first attempt can be largely misaligned with the imagined consumer wants but still profitable. The bar that the promoter needs to initially meet is not impeccable implementation, but better satisfaction of consumers than existing production. The promoter's undertaking is successful if more value is facilitated through his endeavor than previously in the market, through either producing a better (more highly valued) good or reducing the cost of production (or both). "The only source from which an entrepreneur's profits stem is his ability to anticipate better than other people the future demand of the consumers" (Mises [1949] 1998, 288). It does not matter if the production technology can still be (greatly) improved, the offering better positioned, or the business model tweaked. It is possible, if not likely, that the promoter's novel contribution is not initially maximized or efficient, and thus encompasses many and potentially significant "errors" (inefficiencies, both technological and economic) that can be corrected over time by the original promoter or competing entrant entrepreneurs.

This depiction of the promoter is fully compatible with Mises's view:

The driving force of the market, the element tending toward unceasing innovation and improvement, is provided by the restlessness of the promoter and his eagerness to make profits as large as possible. (Mises [1949] 1998, 256)

The promoter is responsible for this "unceasing innovation" that, in Mises's words, "[adjusts] production to the best possible 
supplying of the consumers with the goods they are asking for most urgently" that "does not merely consist in determining the general plan for the utilization of resources" (Mises [1949] 1998, 300; emphasis added). Rather than resource allocative, the role is innovative and disruptive to the structure of production. Thus, rather than improving the effectiveness of the economic system by correcting existing errors, the promoter brings about improvements by revolutionizing the overall structure of production and changing the market data for nonpromoter entrepreneurs, who to earn a profit must respond to this change.

It has been shown, then, that by using the specialization deadlock, an imaginary construction complementary to the ERE, it is not only possible to praxeologically offer a definition for the promoter, but also to distinguish this actor from nonpromoter entrepreneurs.

\section{CONCLUDING DISCUSSION}

The discussion above offers a theoretically sound definition of the promoter as producer of great adjustments of production that distinguishes promoters from nonpromoter entrepreneurs. Although Mises asserted that this is not possible, that the promoter "cannot be defined with praxeological rigor" (Mises [1949] 1998, 256), his conclusion rests on an analysis of entrepreneurship using the ERE. This imaginary construction, however, is inappropriate for distinguishing between types of entrepreneurs, because it excludes all change and, consequently, does not allow for distinction between types (or magnitudes) of change. To alleviate this shortcoming, the specialization deadlock and the theory of how decentralized market production can(not) adopt innovative divisions of labor were instead applied to show that there is a real and theoretically determinable difference between promoters and nonpromoters: the former introduce novel production beyond the current extent of the market and thereby provide direction for the overall structure of production.

What remains is to briefly address what the praxeological determination of the promoter role means in terms of the "driving force of the whole market system." First, the market process following the promoter's realized profits will be addressed, and then the way 
in which Mises's varying uses of the "driving force" come together in the promoter as he is here defined will be shown.

\section{Subsuming the Promoter}

The viability of the promoter's project is temporary. Where successful and earning above regular returns, it will set market processes in motion that undermine and eventually will dissipate the economic profits by attracting other entrepreneurs. These entrepreneurs are eager to share in the profits and thus attempt similar production structures by emulating the promoter's new solution. While emulating the promoter, ${ }^{6}$ they also make adjustments to and so aim to improve on the promoter's original recipe and contribution to consumer welfare by incorporating their own knowledge and expertise. This is partly due to not being able to fully reproduce the promoter's production structure, which, because its parts are not subject to market exchange, could to some extent be hidden. Part of the reason is also that the followers may have different conceptions of what constitutes the actual economic value of the novel production and use their idiosyncratic expertise to further improve on the original attempt. These emulators would therefore need to rely on their own judgment rather than reproduce the original exactly. Although the promoter has provided direction and proof of concept, the emulators are still not acting within a fully formed market but must imitate the promoter's complete project. And to capture the promoter's profits, they must overtake the pioneer in terms of value creation and produce a better offer for customers.

Through these followers' investments in similar structures of production, they augment the impact of the promoter's own actions by further shifting resources in the promoter's indicated direction. As they compete for the same (types of) resources, the follower entrepreneurs, "eager to earn profits, appear as bidders at an

\footnotetext{
${ }^{6}$ The exact role of the follower entrepreneurs is beyond the scope of this paper's discussion. However, it appears their actions constitute a type of arbitrage that goes beyond and is different from regular within-market resource allocation between production processes. Their actions constitute arbitrage between two alternative production structures rather than different production processes: the promoter's newly created structure of production and the existent market. This role should be further analyzed in future research.
} 
auction, as it were, in which the owners of the factors of production put up for sale land, capital goods, and labor" (Mises [1949] 1998, 332). Because of the promoter's realized profits, the followers can bid higher than within-market actors for the needed resources and thereby bid up their market prices. They may also attempt to bid for the promoter's, and each other's, resources and thereby generate market prices for the novel factor specializations. As market prices are determined, the promoter's "island of specialization" eventually disintegrates and the entrepreneurs can replace previously unique "internal" functions with market services (cf. Rothbard [1962, 1970] 2004, 609-16). As a result, the extent of the market is expanded, and the specialization deadlock shifts outward so that the promoter's original contribution is subsumed within what is now the market. By means of the promoter's imagined and implemented production structure, and through the actions of those entrepreneurs eager to capture the his new profits, the market has overcome the previous specialization deadlock.

As we can see, then, the promoter is the instigator of increased specialization intensity in the market, and thus what brings about ever-deeper divisions of labor through leaps forward-not incremental improvements. Promoters are in this sense leaders "in the social division of labor by...directing the factors of production" (Salerno 2008, 195). They do this by establishing "islands of specialization" (Bylund 2016), or intensively specialized production structures that must be implemented beyond the extent of the existing market. These pioneers are thus necessary for and constitute the vanguard of progress in the market process, and promoters are therefore core to understanding the driving force of the market.

\section{Mises on the "Driving Force"}

Mises is often quoted as saying that entrepreneurship is the "driving force" of the market, by which he specifically meant the promoter, as has been shown here. Using the theoretical definition of this role as developed here, further support for this conclusion is found.

Reading Human Action, however, it becomes clear that Mises uses that same phrase in several different ways. It is not immediately obvious that he was referring to one and the same driving force. 
In light of the foregoing discussion and the definition developed above, his references to the "driving force" come together and thus Mises, rather than being inconsistent, appears to really have been referring to important nuances of the very same thing.

In this section three specific uses of the "driving force" are examined and reinterpreted using the definition elaborated in this article.

1. "Profit-seeking speculation is the driving force of the market as it is the driving force of production" (Mises [1949] 1998, 325-26).

Mises here notes not simply that profit seeking is the driving force or that speculation is, but that profit-seeking speculation is. Both profit seeking, in the sense of economic and not merely accounting profits, and speculation in the market process are virtually synonymous with uncertainty bearing. Thus, there is reason to believe that Mises may have been making a deeper point, a suspicion that is further augmented by the reference to production. The distinction made in this article between entrepreneurship within the extent of the market (nonpromoter) and entrepreneurship that breaks free from it (promoter) reveals that there is a significant difference in their speculative undertakings. The former speculates, as does any actor, about future market conditions but only attempts to respond to what is expected. The profit sought is that attainable through discovering opportunities that already exist as "errors" because the economy is not fully equilibrated. Nonpromoters' role is primarily to effect allocation of resources toward those production processes that are expected to become most profitable, not to change production processes.

In contrast, the latter speculates about bringing about a new future by creating new production structures beyond the specialization deadlock and, as a result, disrupting the status quo. Profits are for the promoter not due to corrections or arbitrage opportunities within the normal progression of the market that are attainable through exchange, but are new profits that do not derive from, and may not even be related to, the status quo. In contrast, the followers of the promoter do not speculate about the economic feasibility of the undertaking in the sense that promoters do, because the promoter has already broken the new ground and shown that it is profitable.

The nonpromoters' profits should be relatively temporary, since competitors can rather easily acquire similar (or identical) means 
to copy the what the profiting entrepreneur did. But for the latter, the promoter's profitable undertaking is not easily, and perhaps not even entirely, reproducible, which suggests the original profits may last comparatively longer. Also, improvements to the original innovation can potentially extend profitability by keeping ahead of competitors and/or lowering production cost. It is also possible that follower entreprenuers can sufficiently improve on the original innovation to outcompete the promoter and create renewed (and extended) profitability.

It is possible that Mises had a similar distinction in mind and therefore pointed out profit's role as driving force of the market through its being a driving force of production. This is indeed the implication of our analysis here. Although allocating resources between existing production processes (those that can be established within the extent of the market and, thus, the limitations of the production structure) will shift relative quantities of output, these are adjustments of production in degree, not kind. This is also the case for those entrepreneurs following and attempting to emulate the successful promoter, although their actions adjust the structure of production from the status quo to the novelty created by the promoter. These are all different from the promoters, who break new ground by establishing novel production processes and, as a result, extend the division of labor.

2. "[The free enterprise system's] driving force is the profit-motive the instrumentality of which forces the businessman constantly to provide the consumers with more, better, and cheaper amenities" (Mises [1949] 1998, 611)

This is similar to the quotation above but, in contrast, appears to downplay the distinction between promoters and nonpromoters somewhat and instead elevates the businessman as an important actor in the market process. However, this may be a contextual interpretation.

In a market without promoters, the market is purely "driven" by entrepreneurs' responses to discovered price discrepancies and expected changes. There is little novelty in production and the market lacks the means to disrupt the structure of production-it lacks the means to move beyond the specialization deadlock (i.e., the extent of the market) other than through minor, incremental changes. Although improvements are possible building on previous 
incremental improvements, this is a slow and steady process unable to take the leaps forward provided by promoters (cf. Bylund 2015b). Advanced task splitting and the establishment of new processes that are more than a recombination of already existing tasks are beyond the market's reach without promoters.

But added promoters, who are potentially always present in the free enterprise system, the adjustments carried out by nonpromoting entrepreneurs must always take into account also imagined disruptions by promoters. Empirically, therefore, in markets where there are promoters, all entrepreneurs must adjust their production to the imagined future market conditions that must include also potential disruptions by promoters. In other words, in a market that does not preclude promoters the task for nonpromoters will be much more difficult, because market data can undergo dramatic, promotor-caused change. It may not be sufficient to discover the arbitrage opportunity of a price discrepancy if that discrepancy can be made an irrelevant error (and thus unprofitable) by a promoter's disruptive innovation.

This suggests that in the empirical market, which is always subject to potential disruption, there may be less difference between within-market nonpromoters and those entrepreneurs who emulate promoters. Both would need to position themselves and their businesses with respect to existent "errors," whether those errors exist as price discrepancies between market-priced actions or between market-based and promoter-innovated production. As the former are dissipated by the emergence of the latter, there may be no time-extensive simple arbitrage entrepreneurship in the empirical market.

Also, in this situation, where the market can potentially be disrupted, an entrepreneur who is not herself seeking to disrupt the market may still do so. Consider an entrepreneur who aims to adjust his production to what he imagines will be the true future market conditions using resources already available in the market. $\mathrm{He}$ assumes or must at least account for potential disruptions in his calculations. As a result, his nonincremental positioning, in effect an attempt to exploit an expected price discrepancy emerging from expected (but not yet occurred) disruption, could itself cause a disruption (if the expected disruption does not happen but the 
positioning turns out profitable) to which other entrepreneurs will then have to adapt.

This suggests that there may be less difference empirically between the actions of promoters and nonpromoters than the distinction determined theoretically suggests. In fact, the potential for disruption should increase the difficulty of "regular," nonpromoter entrepreneurship, thereby potentially increasing the burden of uncertainty that they bear.

3. "Profits are the driving force of the market economy" (Mises [1949] 1998, 805)

Similar to the second quote above, it is new economic profits that bring about the change in direction for the market economy. Although resource allocation is undertaken for profit, and changes in consumer preferences can shift profitability across production processes, such profit seeking will only redistribute productive effort. Nonpromoters equilibrate the production structure by earning profits from correction of errors, thus responding to what is.

In contrast, promoters break new ground and attempt to create new profits by disrupting production of existing goods or creating new ones. As discussed above, those new profits created by the promoter then attract follower entrepreneurs who attempt to capture part of the profits by emulating the promoter. The island of specialization that is established beyond the specialization deadlock thereby expands to eventually become subsumed under the general market as entrepreneurial bidding determines market prices for the new factors and processes. While the promoter is the entrepreneur instigating the process by earning above regular profits, the follower entrepreneurs also earn such profits but act to undermine them by bidding up the prices of factors. The followers' profits, however, do not constitute the driving force but are the result of successfully following the promoter. They are also indicative of the end of such profits, since the followers through their actions undermine the promoter's profitability and allow for the remainder of the market to "catch up" with the innovation and subsume the new specialization intensity. The new profits are then extinguished such that there is no remaining economic surplus available from the original innovation. What remains at that point are profits available through correcting the errors made by entrepreneurs in the market-based production 
processes, which should be attainable primarily through arbitrage. Such arbitrage profits do not, however, "drive" the market in any direction other than making comparatively incremental progress toward less costly production (i.e., with fewer/lesser errors).

Finally, it should be noted that it is only the successful promoter that revolutionizes the market. A promoter's failed undertaking does not cause substantial or lasting change to the market. Thus, as Mises notes, it is the profits earned by the promoter that, through profit-seeking follower entrepreneurs, take the market in that particular direction. Promoters suffering losses do not change the course of the market, but can only indicate to potential follower entrepreneurs that the route they chose was not, at least in the way they attempted it, feasible.

\section{The Promoter and Austrian Entrepreneurship Theory}

Finally, it behooves us to briefly comment on the nature of the promoter as the driving force of the market economy from the perspective of contemporary entrepreneurship theory. Austrian entrepreneurship theory has over the past decades been dominated by Israel Kirzner's entrepreneurship as alertness (Kirzner 1973, 1979, 1997). Kirzner borrows from and elaborates on Mises's conception of "pure entrepreneurship" (Mises [1949] 1998, 254); his entrepreneur is primarily an agent responding to and discovering opportunities in the form of errors (inefficiencies) remaining after previous entrepreneurship (Kirzner 1978). This entrepreneur neither owns capital nor can suffer losses but is defined by alertness-the ability to discover opportunities for arbitrage gains. Thus, entrepreneurship is purely equilibrating.

Although Kirzner's alertentrepreneur has been subject to criticism, both in the past (Rothbard 1974; High 1982) and more recently (Foss and Klein 2010; Bylund, forthcoming), there are important similarities between his entrepreneur and Mises's nonpromoter. For example, both are nondisruptive and responsive to change; they strive for improved adaptation through adjustments and reallocations, and they deal primarily with discovering and correcting already existing errors (opportunities) within the market. This is different from the promoter's attempted disruptions. As Salerno $(1993,123)$ notes, "For Mises, the promoter concept goes beyond 
the category of the pure entrepreneur derived from the action axiom." In contrast, "Kirzner's analysis of the market process has no use for the concept of the dynamic promoter-entrepreneur who is perpetually forecasting and appraising the future in quest of anticipated profit opportunities" (Salerno 1993, 127).

The promoter's placing of new production beyond the extent of the market, and thus outside of the specialization deadlock, is the market's "driving force." Entrepreneurial discovery of arbitrage opportunities can only bring the market closer to realizing what is already possible given the present structure of the economy. In other words, these opportunities are profitable corrections to the allocation of resources, a result of previous entrepreneurs' inefficient solutions.

In contrast, the actions of promoters should undermine the alert entrepreneur's attempted equilibratory actions by actively causing change to the market data by disrupting production, introducing new goods, etc. They create, when successful, new profits through novel production that is impossible to undertake within the present market's production structure. In this sense, it seems that Mises's promoter, as compared to the "pure entrepreneur" and the nonpromoter, may have more in common with both Schumpeter's ([1911] 1934) innovator as instigator of "creative destruction" and Lachmann's ([1956] 1978) reformer of the capital structure (see e.g., Horwitz 2019) than with Kirzner's alert entrepreneur.

\section{REFERENCES}

Alvarez, Sharon A., and Jay B. Barney. 2007. "Discovery and Creation: Alternative Theories of Entrepreneurial Action." Strategic Entrepreneurship Journal 1, no. 1-2: 11-26.

Baumol, William J. 1968. "Entrepreneurship in Economic Theory." American Economic Review 58, no. 2: 64-71.

Bylund, Per L. 2011. "Division of Labor and the Firm: An Austrian Attempt at Explaining the Firm in the Market." Quarterly Journal of Austrian Economics 14, no. 2: 188-215.

— . 2015a. "Explaining Firm Emergence: Specialization, Transaction Costs, and the Integration Process." Managerial and Decision Economics 36, no. 4: 221-38. 
. 2015b. "The Realm of Entrepreneurship in the Market: Capital Theory, Production, and Change." Pp. 89-104 in The Next Generation of Austrian Economics: Essays in Honor of Joseph T. Salerno, ed. Per L. Bylund and David Howden. Auburn, Ala.: Ludwig von Mises Institute.

_ 2015c. "Signifying Williamson's Contribution to the Transaction Cost Approach: An Agent-Based Simulation of Coasean Transaction Costs and Specialization. " Journal of Management Studies 52, no. 1: 148-74.

- 2016. The Problem of Production: A New Theory of the Firm. Abingdon, U.K.: Routledge.

_ 2019. "The Austrian Free Enterprise Ethic: A Mengerian Comment on Kirzner (2019)." Review of Austrian Economics. https://doi.org/10.1007/ s11138-019-00496-3.

—_- Forthcoming. "The Firm vs. the Market: Dehomogenizing the Transaction Cost Theories of Coase and Williamson." Strategic Management Review.

Bylund, Susanne C., and Per L. Bylund. Forthcoming. "The Economic Firm as a Manifestation of Strategic Entrepreneurship." In Handbook of Strategic Entrepreneurship, ed. Vishal Gupta, A. Banu Goktan, G. Shirakova and A. Karna. Northampton, Mass.: Edward Elgar Publishing.

Coase, Ronald H. 1937. "The Nature of the Firm." Economica 4, no. 16: 386-405.

Durkheim, Émile. [1892] 1933. The Division of Labor in Society. New York: The Free Press.

Foss, Nicolai J., and Peter G. Klein. 2010. "Alertness, Action, and the Antecedents of Entrepreneurship." Journal of Private Enterprise 25, no. 2: 145-64.

Hayek, Friedrich A. von. 1945. "The Use of Knowledge in Society." American Economic Review 35, no. 4: 519-30.

Hébert, Robert F., and Albert N. Link. 1988. The Entrepreneur: Mainstream Views and Radical Critiques. New York: Praeger.

High, Jack. 1982. “Alertness and Judgment: Comment on Kirzner.” Pp. 161-68 in Method, Process, and Austrian Economics: Essays in Honor of Ludwig von Mises, ed. Israel M. Kirzner. Lexington, Mass.: Lexington Books. 
Horwitz, Steven. 2019. "Ludwig Lachmann as a Theorist of Entrepreneurship." Studies in Logic, Grammar and Rhetoric 57, no. 1: 19-40.

Kirzner, Israel M. 1973. Competition and Entrepreneurship. Chicago: University of Chicago Press.

—. 1978. "Economics and Error." In New Directions in Austrian Economics, edited by Louis M. Spadaro, 57-76. Kansas City, MO: Sheed Andrews and McMeel.

- 1979. Perception, Opportunity, and Profit: Studies in the Theory of Entrepreneurship. Chicago: University of Chicago Press.

— 1992. The Meaning of the Market Process. London: Routledge.

—. 1997. "Entrepreneurial Discovery and the Competitive Market Process: An Austrian Approach." Journal of Economic Literature 35, no. 1: 60-85.

_ 2009. "The Alert and Creative Entrepreneur: A Clarification." Small Business Economics 32, no. 2: 145-52.

Klein, Peter G., and Per L. Bylund. 2014. "The Place of Austrian economics in Contemporary Entrepreneurship Research." Review of Austrian Economics 27, no. 3: 259-79.

Lachmann, Ludwig M. [1956] 1978. Capital and Its Structure. Kansas City, Kans.: Sheed Andrews and McMeel.

Land, Kenneth C. 1970. "Mathematical Formalization of Durkheim's Theory of Division of Labor." Sociological Methodology 2: 257-82.

Menger, Carl. [1871] 2007. Principles of Economics. Trans. James Dingwall and Bert F. Hoselitz. Auburn, Ala.: Ludwig von Mises Institute.

Mises, Ludwig von. [1949] 1998. Human Action: A Treatise on Economics. Scholar's ed. Auburn, Ala.: Ludwig von Mises Institute.

Rothbard, Murray N. 1974. Review of Competition and Entrepreneurship, by Israel M. Kirzner. Journal of Economic Literature 12, no. 3: 902-04.

- 1991. Freedom, Inequality, Primitivism, and the Division of Labor. Auburn, Ala.: Ludwig von Mises Institute.

- $[1962,1970]$ 2004. Man, Economy, and State with Power and Market. Scholar's ed. Auburn, Ala.: Ludwig von Mises Institute. 
Salerno, Joseph T. 1993. "Mises and Hayek Dehomogenized." Review of Austrian Economics 6, no. 2: 113-46.

_ 2008. "The Entrepreneur: Real and Imagined." Quarterly Journal of Austrian Economics 11, no. 3: 188-207.

Schumpeter, Joseph A. [1911] 1934. The Theory of Economic Development: An Inquiry into Profits, Capital, Credit, Interest, and the Business Cycle. Cambridge, Mass.: Harvard University Press.

—_ [1934] 1961. The Theory of Economic Development: An Inquiry into Profits, Capital, Credit, Interest, and the Business Cycle. Trans. Redvers Opie. New York: Oxford University Press.

- 1947. Capitalism, Socialism, and Democracy. 2d ed. New York: Harper and Bros.

Shane, Scott. 2003. A General Theory of Entrepreneurship: The IndividualOpportunity Nexus. Cheltenham, U.K.: Edward Elgar.

Shane, Scott, and Sankaran Venkataraman. 2000. "The Promise of Entrepreneurship as a Field of Research. "Academy of Management Review 25, no. 1: 217-26.

Smith, Adam. [1776] 1976. An Inquiry into the Nature and Causes of the Wealth of Nations. Ed. Edwin Cannan. Chicago: University of Chicago Press.

Townsend, David M., Richard A. Hunt, Jeffery S. McMullen, and Saras D. Sarasvathy. 2018. "Uncertainty, Knowledge Problems, and Entrepreneurial Action." Academy of Management Annals 12, no. 2: 659-87.

Witt, Ulrich. 1998. "Imagination and Leadership: The Neglected Dimension of an Evolutionary Theory of the Firm." Journal of Economic Behavior and Organization 35: 161-77. 